Brit. J. vener. Dis. (1958), 34, 58.

\title{
OBITUARY
}

\section{JOSEPH EARLE MOORE}

News of the death of Earle Moore has brought sadness to his many friends in Great Britain and throughout the world.

He was born in Philadelphia on July 9, 1892, and graduated B.A. from the University of Kansas in 1914 and, in medicine, at Johns Hopkins University in 1916. In the latter part of the first world war he served in France in the Medical Corps of the American Expeditionary Force. Before the Force became effective he was attached for a time to a British field ambulance, and it was the warmth and friendliness of his reception by British colleagues at that time which did much to establish the lifelong regard and affection in which he held this country. After the war he returned to the Johns Hopkins University and Hospital to which he was destined to give distinguished service until the time of his death. He was a general physician but his special interest was the venereal diseases. He became professor of Medicine in the Johns Hopkins School of Medicine being the first practising physician to be named as full professor, and was also adjunct professor of public health administration at the school of hygiene and public health of the University. His department, "Medicine I", at the Johns Hopkins Hospital became famous throughout the world as the result of his publications and of the research work which he directed so ably. He was a pioneer teacher in methods of venereal disease control and his former students hold important positions in the subject throughout the United States and in many parts of the world. He was the author of textbooks entitled "The Modern Treatment of Syphilis" and "Penicillin in Syphilis", and editor for many years of the American Journal of Syphilis, Gonorrhoea and Venereal Diseases, until publication was discontinued in 1954, and he became editor of the Journal of Chronic Diseases. During the second world war he was adviser on venereal diseases control to the
Surgeons General of the Armed Forces and Public Health Service of the United States, and was chairman of the Sub-committee on Venereal Diseases of the National Research Council. For these services he was awarded the Medal of Merit of the United States in 1946. He was director, guide, and ruling spirit of the intensive research into the use of penicillin in the treatment of syphilis which, as the result of cooperative efforts by American physicians in the United States Public Health Service, provided, during the late 1940 's, most complete and valuable information which otherwise might have taken many years to acquire. He was a clear and original thinker, an excellent speaker, and a brilliant writer. So great was the affection and respect in which he was held by his colleagues that on his 60th birthday, in 1952, a dinner was held in Washington under the chairmanship of Dr. Thomas Parran, formerly Surgeon General to the United States Public Health Service, to commemorate the event. More than a hundred distinguished colleagues attended to do him honour. He visited the United Kingdom nearly every year and was an honorary member of the Medical Society for the Study of Venereal Diseases, which he addressed on a number of occasions, including two important meetings held jointly by the Society and the Section of Experimental Medicine of the Royal Society of Medicine. In 1950 he was the Malcolm Morris Memorial lecturer. His most recent visit to London was in the summer of 1957 when he knew himself to be dying, but he faced the last painful months with the utmost courage and determination. He died on December 6, 1957, in the Johns Hopkins Hospital which he had served so well and so devotedly.

His friends in this country and many others will remember him for his staunch loyalty and affection, for his generosity and for his warm and thoughtful hospitality, here and in his home in 
Baltimore. In the latter respect he was outstanding even by American standards. He was a man of great force of character and an example and an inspiration to the many young men who came under his influence, including a number from Great
Britain who held fellowships in his department. In his own subject he stood head and shoulders above his contemporaries and his passing marks the end of an era in venereology in which he was the outstanding figure.
A.J.K.

\section{BOOK REVIEW}

Non-Venereal Syphilis. A Sociological and Medical Study of Bejel. By Ellis Herndon Hudson. 1958. Pp. 212, 106 figs. Livingstone, Edinburgh and London (30s.)

Dr. Hudson gave the outside world the term "bejel" which was the local word for a disease prevalent amongst Bedouin peasants which he recognized as a treponematosis. He studied this treponematosis closely during his 12 years' work as a medical missionary in the small Arab town of Deir-ez-Zor. This book is written about this experience and is based on the records of the bejel patients seen during his service amongst these Arab peoples, between 1924 and 1937. To those who have not read his previous monograph entitled "Treponematosis" -now out of print-this new publication will provide an opportunity of learning about his "unitarian" hypothesis of the origin of the treponematoses.

The substance of the book falls into three parts: the historical perspective of treponematosis, the clinical and serological picture of bejel in the three social groups of the Arab community in Deir-ez-Zor, and the particular form of treponematosis affecting each group. Modern transport has since brought the Bedouin to the town and has thus influenced his diseases, making the three social groups described by Hudson harder to recognize. This development lends added value to this book as a record of the social pattern of an Arab community a generation ago. Bejel is described as a disease confined to the Bedouin, the nomad of the desert; in recent years at any rate it has been found to be equally prevalent, if not more so, amongst the static tribes, e.g. in the Jeboors who live along the banks of the Euphrates and Tigris. In fact, during 1951-52, the WHO team in Iraq found the highest incidence in the marsh Arabs.

The section on the clinical picture of bejel and its illustrations are both excellent. For those familiar with yaws, it provides an interesting comparison. The serological section has been written by Dr. Tuomioja, who was the Laboratory Adviser to the WHO, Bejel/Syphilis Project in Iraq (1950-51). In the main, the serology of bejel does not differ essentially from that of venereal syphilis.

The book contains a very interesting chapter on the experimental pathology of bejel incorporating extracts from "The Biology of the Treponematosis" by Turner and Hollander*. Venereologists and Sociologists will find this chapter particularly instructive and illuminating.

Dr. Hudson has written this book for the sociologist and anthropologist as well as for those directly concerned with the treponematosis. Whether or not one accepts the author's main hypothesis, the book provides interesting reading.

L.G.G.J.

\footnotetext{
* Reviewed in this Journal (1957), 33, 199.
} 